\title{
Darstellung des Liq. Ferri oxychlorati.
}

Von Wilh. Weber, Apotheker in Lich.

Während dieses Eisenpräparat früher als Liq. Ferri dialysati bekannt war und sehr umständlich durch Dialyse hergestellt wurde, hat die Pharmakopöe dasselbe aufgenommen und mit Rücksicht auf seine Constitution als Liq. Ferri oxychlorati aufgeführt. Jedenfalls haben wir in diesem Präparat eines jener basischen Salze vor uns, wie sie auch bei anderen Metallen, z. B. Kupfer und Blei rorkommen und welche man als Salze der sogen. Polyhydrate betrachten muss. Unter Polyhydraten sind bekanntlich diejenigen Hydroxyl-Verbindungen zu verstehen, welche durch Zusammentreten mehrerer Mol. einer polyhydrischen Base unter Austritt von Wasser entstehen, analog der Bildung der Poly- oder Anhydro-Säuren der mehrbasischen Säuren.

Wer sich mit der Darstellung dieses Präparates befasst und dabei die chemischen Vorgänge verfolgt hat, dem muss es aufgefallen sein, dass die Pharmakopöe zur Auflösung des gewaschenen und ausgepressten Eisenhydroxydes Salzsäure anwenden lässt. Diese Salzsäure wird nothwendig mit dem Eisenhydroxyd zuerst Eisenchlorid bilden müssen, welches dann mit woiterem Eisenhydroxyd das oben näher bezeichnete basische Chlorid resp. das Poly-Oxychlorid bildet. Wenn nun beim Zusammentreffen der Salzsäure mit dem Eisenhydroxyd doch zuerst Eisenchlorid entsteht, so ist, wie mir scheinen will, kein Grund vorhanden, warum das Chlor in Form von Salzsäure und nicht gleich als Eisenchlorid eingeführt werden sollte.

Der Vortheil, den die Abänderung der gegebenen Vorschrift in diesem Sinne gewährt, liegt auf der Hand, denn es wird durch die Anwendung der Eisenchloridlösung anstatt der Salzsäure nicht allein letztere gespart, sondern zugleich noch eine neue Quantität der ersteren in Liq. Ferri oxychlorati verwandelt. Wenn dies auch keinen besonders grossen Vortheil bietet, so ist es jedenfalls rationeller und schon aus diesem Grunde zu empfehlen. Hiernach wäre also die Vorschrift der Pharmakopöe so abzuändern, dass anstatt 3 Thln. Salzsäure 3,9 Thle. Liq. Ferri sesquichlorati zu verwenden wären. Ich habe auf diese Weise den Liquor schon mehrmals hergestellt und wie vorauszusehen ein ganz tadelloses Präparat erhalten. 